\title{
Contribution of pollen to atmospheric ice nuclei concentrations
}

\author{
J. D. Hader, T. P. Wright, and M. D. Petters \\ Department of Marine, Earth, and Atmospheric Sciences, North Carolina State University, Raleigh, North Carolina, USA \\ Correspondence to: M. D. Petters (markus_petters@ncsu.edu)
}

Received: 20 November 2013 - Published in Atmos. Chem. Phys. Discuss.: 4 December 2013

Revised: 31 March 2014 - Accepted: 16 April 2014 - Published: 4 June 2014

\begin{abstract}
Recent studies have suggested that the icenucleating ability of some types of pollen is derived from non-proteinaceous macromolecules. These macromolecules may become dispersed by the rupturing of the pollen grain during wetting and drying cycles in the atmosphere. If true, this mechanism might prove to be a significant source of ice nuclei (IN) concentrations when pollen is present. Here we test this hypothesis by measuring ambient IN concentrations from the beginning to the end of the 2013 pollen season in Raleigh, North Carolina, USA. Air samples were collected using a swirling aerosol collector twice per week and the solutions were analysed for ice nuclei activity using a droplet freezing assay. Rainwater samples were collected at times when pollen grain number concentrations were near their maximum value and analysed with the drop-freezing assay to compare the potentially enhanced IN concentrations measured near the ground with IN concentrations found aloft. Ambient ice nuclei spectra, defined as the number of ice nuclei per volume of air as a function of temperature, are inferred from the aerosol collector solutions. No general trend was observed between ambient pollen grain counts and observed IN concentrations, suggesting that ice nuclei multiplication via pollen grain rupturing and subsequent release of macromolecules was not prevalent for the pollen types and meteorological conditions typically encountered in the southeastern US. A serendipitously sampled collection after a downpour provided evidence for a rain-induced IN burst with an observed IN concentration of approximately 30 per litre, a 30-fold increase over background concentrations at $-20^{\circ} \mathrm{C}$. The onset temperature of freezing for these particles was approximately $-12^{\circ} \mathrm{C}$, suggesting that the icenucleating particles were biological in origin.
\end{abstract}

\section{Introduction}

Primary biological aerosol particles (PBAP) derived from living and dead biological microorganisms are routinely observed in the atmosphere (Després et al., 2012). These particles can aid the nucleation of cloud droplets and ice crystals (Schnell and Vali, 1976; Möhler et al., 2007; Ariya et al., 2009) and thereby indirectly influence the Earth's climate system (Andreae and Rosenfeld, 2008). A small fraction of biological particles carry a protein that nucleates ice at temperatures slightly below $0{ }^{\circ} \mathrm{C}$ (Lagriffoul et al., 2010). Evidence of the presence of these proteins has been found in rain and snow samples (Christner et al., 2008a, b). The extent to which these potent nuclei will interfere with cloud processes depends however on their abundance in the atmosphere and the temperature at which they induce freezing. In general, emission sources for PBAP are spatially and temporally heterogeneous and emission profiles depend on the specific source, the state of the biosphere, and meteorological conditions. To date only few studies have focused on linking atmospheric PBAP with ice nuclei (IN) activity. For example, recent field studies demonstrated that PBAP significantly contributed to ice nuclei concentrations (at $T \sim-20^{\circ} \mathrm{C}$ ) at the surface of the Amazon rainforest (Prenni et al., 2009) and at high altitude over desertic Wyoming at $T \sim-30^{\circ} \mathrm{C}$ (Pratt et al., 2009). Ice nuclei concentrations near the ground increased 40-fold after rain events and correlated highly with PBAP measurements during the BEACHON-RoMBAS (Biohydro-atmosphere interactions of Energy, Aerosols, Carbon, $\mathrm{H}_{2} \mathrm{O}$, Organics \& Nitrogen-Rocky Mountain Biogenic Aerosol Study) field campaign (Prenni et al., 2013; Huffman et al., 2013).

Pollen forms a subset of the primary biological aerosol that can nucleate ice. For the purposes of this paper, the term "pollen grain" refers to the whole intact pollen particle 
released by the plant. Pollen grains are released over a period of 2-4 weeks (Williams, 2010) and can be transported as far as $3000 \mathrm{~km}$ from the emission source (Campbell et al., 1999). Most species require supercooling to temperatures colder than $-20^{\circ} \mathrm{C}$ in order to induce freezing (Diehl et al., 2002; Pummer et al., 2012; Augustin et al., 2013). Select species contain low fractions of grains (1 in 1000) that induce freezing at temperatures as high as $-9^{\circ} \mathrm{C}$ (Diehl et al., 2002). Pummer et al. (2012) show that the ice-nucleating activity of pollen is derived from non-proteinaceous macromolecules contained on or within the grain. Grass pollen can produce cytoplasmic debris on contact with water by osmotic shock that can be separated from the pollen grain as micron- and submicron-sized starch granules and produce up to 700 starch granules per pollen grain (Suphioglu et al., 1992). A wetting-drying cycle consisting of changes in relative humidity from $\sim 60 \%$ to $>90 \%$ back to $\sim 60 \%$ produces aerosolized fragmented cytoplasm (Taylor et al., 2002). The approximate size ranges of the released particles are between 0.2 and $5 \mu \mathrm{m}$. Similar mechanisms may release submicron particles from birch, alder, and hazel pollen grains (Grote et al., 2003). Because the ice-nucleating activity may emanate from suspendable macromolecules that can be extracted from the pollen grain, Pummer et al. (2012) hypothesize that the aerosolized fragmented cytoplasm may lead to significant heretofore underestimated ice nuclei emissions.

Here we test this hypothesis by investigating correlations of ice nuclei spectra with pollen grain concentrations during the 2013 pollen season. Air samples were collected using a swirling aerosol collector approximately twice per week and the solutions were analysed for ice nuclei activity using a drop-freezing assay. Rainwater samples were collected during rain events near the time when tree pollen grain concentrations peaked and were analysed similarly. We quantify the IN concentration per volume of liquid using the method of Vali (1971) and use it to derive ambient ice nuclei concentration per volume of air. The resulting IN spectra are interpreted in the context of the evolution of the pollen season.

\section{Methods}

\subsection{Experimental procedures}

Aerosol was sampled at North Carolina State University throughout April 2013 during the peak of the pollen season. We define the pollen season as the period of time when the NC Division of Air Quality operates the pollen sampler, which is typically from late February through midNovember. The month of April has historically contained the peak of the tree pollen season for central NC, with pollen grain number concentrations increasing approximately 50fold over the course of a week (North Carolina Division of Air Quality, 2010). An all-glass swirling aerosol collector (Bioaerosol sampler; SKC Inc.), hereafter abbreviated as SAC, was placed on the roof of Jordan Hall: a fivestorey building located $\sim 3 \mathrm{~km}$ west of the city centre of Raleigh, NC, USA. The collector consists of three tangential nozzles that direct airborne particles toward a liquid water surface where they impinge and form an aqueous solution/suspension. Particle collection efficiencies for this technique exceed $80 \%$ for particles larger than $200 \mathrm{~nm}$ and approach $100 \%$ for particles larger than $1 \mu \mathrm{m}$ (Willeke et al., 1998). The sample cup was filled with $20 \mathrm{~mL}$ of ultrapure water and air was sampled at a flow rate of $12.5 \mathrm{~L} \mathrm{~min}^{-1}$ over an interval of 3 to $5 \mathrm{~h}$. During the sampling period some fraction of the collection water evaporated, which can reduce the collection efficiency of SAC samplers. Therefore the flow was stopped temporarily every hour and the collection well was refilled by spraying ultrapure water through the collection inlet. This has the added benefit of washing any particles that impacted and remained on the collection inlet into the collection well (see Appendix A for details). It should be noted that this procedure was not performed after the last hour of measurement. Sampling times of the SAC are summarized in Table 1. Two rain events occurred near the time of peak pollen grain concentrations. For these events rainwater was collected by placing cleaned, glass Pyrex dishes on the roof of the building. Sampling protocols were identical to those described previously (Wright et al., 2013). Ice nuclei activity was determined as quickly after collection as time permitted. If immediate processing of the SAC solution was not possible, samples were stored in the refrigerator $\left(+4^{\circ} \mathrm{C}\right)$ for up to 3 days. Rainwater samples for the 19 April event were frozen $\left(-17^{\circ} \mathrm{C}\right)$ and analysed two weeks later. Freezing and thawing of this rainwater sample is unlikely to cause systematic active site modification for any nuclei in the sample (Wright et al., 2013). Rainfall totals were obtained from the on-site weather station that is operated and maintained by the North Carolina State Climate Office.

Ambient pollen grain concentrations were obtained from the North Carolina Department of Environmental and Natural Resources Division of Air Quality ambient monitoring programme (North Carolina Division of Air Quality, 2010). Briefly, pollen grains are collected with a rotating arm impactor using silicone-greased collection rods (Elander and Gebhard, 2004), stained, and counted. The programme reports $24 \mathrm{~h}$ average pollen grain concentrations (no. of grains $\mathrm{m}^{-3}$ air) for the city of Raleigh on weekdays and differentiates between tree, grass, and weed pollen. Diurnal variations in pollen concentration are not captured. Pollen emissions typically peak during daytime (Ogden and Hayes, 1969), coinciding with the SAC measurements (Table 1). Consequently, the reported $24 \mathrm{~h}$ average pollen concentration likely underestimates the actual pollen concentration during the sampling period. Raleigh is located in the east-central portion of North Carolina, USA. The climate is temperate and humid sustaining a dense mixed hardwood forest composed primarily of oak, hickory, and pine species that surrounds the city (LeGrand and Wiecek, 2003). Ambient pollen from 
Table 1. Summary of swirling aerosol collector sampling times.

\begin{tabular}{lrrrrrr}
\hline $\begin{array}{l}\text { Sample } \\
\text { date }\end{array}$ & $\begin{array}{r}\text { Start } \\
\text { time }\end{array}$ & $\begin{array}{r}\text { End } \\
\text { time }\end{array}$ & $\begin{array}{r}\text { Time } \\
\text { elapsed } \\
(\mathrm{min})\end{array}$ & $\begin{array}{r}\text { Volume } \\
\text { sampled } \\
\left(\mathrm{m}^{3}\right)\end{array}$ & $\begin{array}{r}\text { Estimated } \\
\text { final volume } \\
(\mathrm{mL})\end{array}$ & $\begin{array}{r}\text { Ambient pollen } \\
\text { concentration } \\
\text { grains (L air) }\end{array}$ \\
\hline 2 April & $15: 04$ & $18: 50$ & 216 & 2.70 & 13 & 0.04 \\
8 April & $11: 15$ & $18: 46$ & 431 & 5.39 & 12 & 1.10 \\
10 April & $15: 40$ & $21: 30$ & 220 & 2.75 & 7 & 1.71 \\
12 April* & $14: 46$ & $18: 15$ & 193 & 2.41 & 10 & 1.62 \\
16 April & $11: 39$ & $15: 07$ & 199 & 2.49 & 13 & 0.73 \\
19 April* & $10: 36$ & $14: 40$ & 236 & 2.95 & 11 & 1.14 \\
25 April & $10: 57$ & $15: 06$ & 244 & 3.05 & 6 & 0.33 \\
\hline
\end{tabular}

* Pollen counts not available from the NC Department of Air Quality for these time periods. Pollen counts from the previous $24 \mathrm{~h}$ time period used for these days.

local sources during this time period in the Raleigh area is dominated by tree pollen. Some unknown fraction of pollen may have originated from long-range transport into the region (Gregory, 1978; Noh et al., 2013).

Ice nuclei spectra of immersion mode freezing are determined on a drop-freezing assay (Wright and Petters, 2013; Wright et al., 2013). A $15 \mu \mathrm{L}$ aliquot of bulk sample water (water from the SAC or rainwater) is mixed with squalene, emulsified using a vortex mixer, and poured onto a siliconized glass cover slide that is placed inside an aluminium dish. This method produces 500 to 800 droplets with volumes ranging from less than $250 \mathrm{pL}(D=78.2 \mu \mathrm{m})$ to as high as $600 \mathrm{pL}(D=104.6 \mu \mathrm{m})$. Droplets in this size range will be referred to as picodrops. The dish is placed inside a sealed cell made out of polyoxymethylene that is continuously flushed with dry nitrogen gas to prevent condensation of water during the cooling process. The bottom of the cell contains an aluminium insert that thermally bridges a thermoelectric element placed below the cell and the aluminium dish that resides within the cell. A thermistor is mounted inside the bridging aluminium piece to measure the temperature. The dish is cooled at a rate of $1 \mathrm{~K} \mathrm{~min}^{-1}$, and the freezing of droplets is observed via sequential imaging of the slide at 1 frame per $10 \mathrm{~s}$ using a stereomicroscope. The cooling rate of $1 \mathrm{~K}$ per minute was chosen because it approximates cooling rates in moderate updrafts in convective clouds while providing sufficiently fast processing of samples in the lab. For example, a $2.5 \mathrm{~m} \mathrm{~s}^{-1}$ updraft and a moist adiabatic lapse rate of $6.6 \mathrm{~K} \mathrm{~km}^{-1}$ lead to a cooling rate of $1 \mathrm{~K} \mathrm{~min}^{-1}$. Furthermore, freezing spectra derived from cold-stage experiments are only weakly dependent on the cooling rate (e.g. Wright et al., 2013). An illustrative image of the glass slide with picodrops adhered to its surface and examples of frozen and unfrozen picodrops are shown in Fig. 1a. A user-guided imageprocessing algorithm described in detail in Wright and Petters (2013) is used to detect freeze events. From these data, a cumulative spectrum of fraction of droplets frozen versus temperature is constructed. Figure 1c shows an example of a processed picodrop experiment spectra for in-house gener-
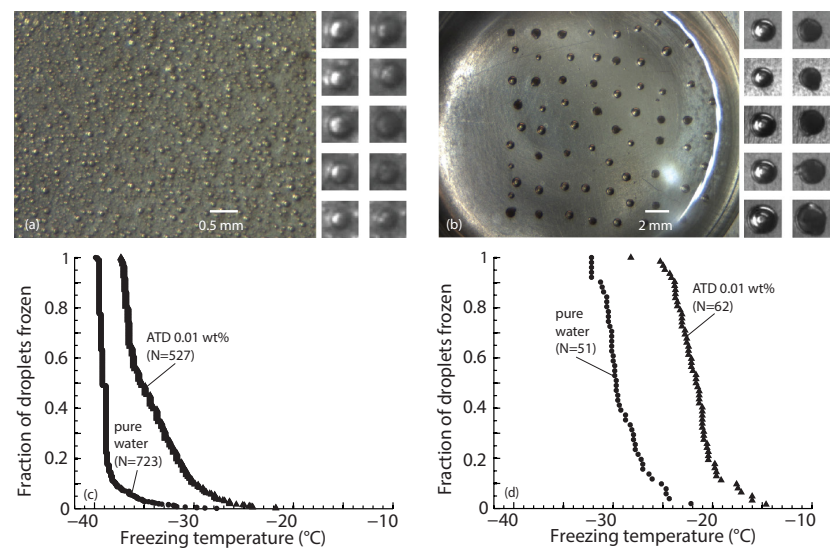

Figure 1. (a) A section of the field of view for a picodrop experiment. The small images to the right depict enlarged examples of individual picodrops prior to freezing (left column) and after freezing (right column). (b) Field of view recorded for a nanodrop experiment; the columns to the right are similar to those in (a). (c, d) Fraction of droplets frozen versus temperature for picodrop and nanodrop experiments, respectively, of both pure water and a $0.01 \mathrm{wt} \%$ suspension of ATD.

ated ultrapure water (18.2 $\mathrm{M} \Omega$ resistivity) and a suspension of $0.01 \mathrm{wt} \%$ of Arizona Test Dust (ATD) in ultrapure water. The addition of ATD to the sample leads to a shift of the median freezing temperature of the population. The magnitude of the shift depends on the weight fraction of dust in the suspension, the droplet size distribution, and the intrinsic efficiency of the immersed ice nuclei (Wright and Petters, 2013).

To sample more rare ice nuclei, experiments with larger volume droplets are performed. For these experiments, $2 \mathrm{~mL}$ of squalene is placed on the glass cover slide inside the aluminium tray. Droplets with volumes of $\sim 150 \mathrm{~nL}(\sim 650 \mu \mathrm{m}$ diameter) are placed with a syringe needle tip on the surface of the squalene and allowed to sink to the squalene-glass interface. Droplets of this size are referred to as nanodrops. To avoid interference between droplets, only 50-75 droplets 
can be placed in the field of view of the camera for a single experiment. A full field-of-view image for a nanodrop experiment and example cumulative spectra derived from nanodrop experiments are shown in Fig. $1 \mathrm{~b}$ and d, respectively. As expected the median freezing temperature is warmer for the nanodrops due to their larger droplet volume because of an increased number of ice-nucleation-active sites present. Combined picodrops and nanodrops can be used to construct a more complete ice nuclei spectrum discussed further below (see also O'Sullivan et al., 2013).

Droplet volumes for picodrops and nanodrops are estimated from the optical image assuming that the imaged droplets are spherical. The projected area per pixel is calibrated using an image of a test object of known dimensions and varied between 5 and $10 \mu \mathrm{m}$ per pixel depending on the selected level of magnification. Possible optical distortion due to refraction is accounted for by submersing the test object below the squalene. Typical droplet volume statistics were $400 \pm 20 \mathrm{pL}(D=91.4 \pm 33.7 \mu \mathrm{m})$ and $145 \pm 10 \mathrm{~nL}(D=652 \pm 267 \mu \mathrm{m})$ for picodrops and nanodrops, respectively.

Temperature is recorded via a thermistor located at the bottom of the cell. Since the surface of the squalene is at a warmer temperature than the aluminium support that the thermistor resides in, there exists a temperature gradient within the squalene. To account for this temperature gradient, a cooling-rate-dependent empirical calibration is applied. The calibration is obtained by placing a second thermistor in the squalene and cooling the instrument. This calibration is applied only to the temperature of the nanodrops as these droplets are close to the size of the thermistor and the droplets appear to have limited contact with the glass slide (the droplets easily slide when shaking the dish) and thus should take on the temperature of the squalene. In contrast, picodrops are assumed to be close to the temperature of the aluminium substructure due to their apparent adhesion to the glass slide and the fact that the aluminium and glass should be at close to the same temperature due to their relatively high thermal conductivity in comparison to the squalene.

All glassware is cleaned using the following procedure prior to use. The glassware is first rinsed with a mixture of bleach and tap water, followed by rinses with tap water and laboratory grade isopropyl alcohol (Fisher Scientific). A bath of $96 \%$ sulfuric acid solution (Acros Organics) is applied (for cleaning of the aerosol collector, a $0.5 \mathrm{M}$ sulfuric acid solution was used instead), followed by rinsing with ultrapure water $(18.2 \mathrm{M} \Omega)$ and a final rinse with isopropyl alcohol. The glassware is then dried at $\sim 90^{\circ} \mathrm{C}$. Between uses, the aluminium tray for the drop-freezing assay is rinsed with tap water followed by a rinse with isopropyl alcohol. Hydrophobic glass slides are generated by first cleaning microscope slip covers following the above method (excepting the bleach and tap water rinses) and then coating them with AquaSil siliconizing fluid (TS-42799, Thermo Scientific) as specified by the manufacturer.
A representative tree pollen sample (Pinus taeda, loblolly pine) was collected from the campus of NC State on 10 April 2013. Whole male strobili were harvested and stored in a sealed bag at $4{ }^{\circ} \mathrm{C}$ until analysis on 6 August 2013. The strobili were rubbed inside of the bag in order to dislodge the pollen grains. A sample of $0.1 \mathrm{~g}$ of this dislodged material was massed out and suspended in $\sim 12 \mathrm{~g}$ of ultrapure water. This suspension was vortexed for 1 to $2 \mathrm{~min}$, and freezing spectra were determined using the picodrop and nanodrop techniques. Pollen grain number concentrations in the suspension were estimated by placing $1-2.5 \mu \mathrm{L}$ of the suspension on filter paper followed by imaging of the filter using a stereomicroscope and counting the number of particles with $D>\sim 10 \mu \mathrm{m}$. From these measurements we estimated a minimum particle concentration of $\sim 20$ particles $\mu \mathrm{L}^{-1}$ of suspension, averaged over four repeated measurements of these 1-2.5 $\mu \mathrm{L}$ samples. Not all particles counted were necessarily intact pollen grains. Agitation of the suspension through vortexing and shaking (in order to achieve a well-mixed solution) may have caused breakup of cellular debris.

\subsection{Ice nuclei analysis methods}

In the following section we describe how ice nuclei spectra, defined as the number of ice nuclei per volume of sample water at a supercooling temperature, are reconstructed from the raw data shown in Fig. 1c and d. Conversion from fraction of droplets frozen to IN concentration is achieved using statistical analysis. Results in Fig. 1c and d are a measure of the fraction of a population of quasi-monodisperse droplets that freeze at the instrument-determined temperature. Each droplet contains an unknown number of ice-nucleating particles. Furthermore, each IN particle induces freezing at a supercooling temperature that depends on its size and chemical composition. The average number of IN per droplet, $\lambda(T)$, is

$\lambda(T)=V_{\mathrm{drop}} c_{\mathrm{IN}}(T)$,

where $V_{\text {drop }}$ is the volume of the droplet, $T$ is the temperature, and $c_{\mathrm{IN}}(T)$ is the concentration of IN suspended in the liquid that induce freezing at a specified level of supercooling. The fraction of the population that is frozen is modelled using the Poisson probability distribution,

$P[k, \lambda(T)]=\frac{\lambda(T)^{k} e^{-\lambda(T)}}{k !}$.

In Eq. (2), $P[k, \lambda(T)]$ is the probability that $k$ droplets of a population are frozen. Consequently, the fraction of droplets that remain unfrozen is $P[k=0, \lambda(T)]$. Observationally, the unfrozen fraction is

$f_{\text {unfrozen }}=\frac{n_{\text {unfrozen }}(T)}{n_{\text {total }}}$,

where $n_{\text {unfrozen }}(T)$ is the number of droplets that remain unfrozen at supercooling $T$ and $n_{\text {total }}$ is the total number of 
droplets in the cold stage. Combining Eqs. (1)-(3) and solving for $c_{\mathrm{IN}}(T)$ yields

$c_{\mathrm{IN}}(T)=-\frac{\ln \left(f_{\text {unfrozen }}\right)}{V_{\text {drop }}}$,

which is identical to Eq. (13) in Vali (1971). Equation (4) shows that the concentration of ice nuclei in the liquid can be derived from population freezing statistics of monodisperse droplets. More numerous droplet populations permit the observation of lower unfrozen fractions and therefore lower the detection limit of IN concentrations. Similarly, populations with larger droplet volumes also improve the limit of detection.

The following implicit assumptions were made in the derivation of Eq. (4). First, it is assumed that the droplet distribution is monodispersed, i.e. that all droplets have identical volume. Second, it is assumed that each droplet contains $n$ aerosol particles, where $n$ scales with the volume of the droplet and the particles within each droplet are representative of the bulk sample from which it was created. This is true for a well-mixed aqueous suspension and is reasonable for the SAC and rainwater samples. Third, it is assumed that each particle has a characteristic temperature at which it induces freezing of the surrounding water. This deterministic behaviour implies that the observed freezing temperature of the droplet is independent of the cooling rate. Although ice nucleation is fundamentally cooling-rate-dependent, data for a wide range of different types of ice nuclei (including those found in rainwater) indicate that varying the cooling rate by an order of magnitude leads to shifts ranging from 0 to $2 \mathrm{~K}$ in observed population median freezing temperatures (Vali, 1994; Wright et al., 2013; Knopf and Alpert, 2013). Assuming deterministic or singular freezing behaviour will lead to an error commensurate with the deviation from the cooling rate of $1 \mathrm{~K} \mathrm{~min}^{-1}$ used in this study. Fourth, it is assumed that the characteristic freezing temperature is not affected by other particles residing in the same droplet volume, i.e. that all characteristic temperatures are statistically independent. This may appear to be in contradiction to experiments that demonstrate that the deposition of organic compounds or sulfuric acid on individual particles can suppress deposition ice nucleation (Möhler et al., 2008; Sullivan et al., 2010b; Koehler et al., 2010; Chernoff and Bertram, 2010). Nevertheless, the detrimental effect of coatings on IN activity is less pronounced or non-existent for immersion freezing (Sullivan et al., 2010a, b). Both SAC solutions and rainwater samples are dilute, suggesting that chemical attack or physical shielding of active sites by coatings have only minor influence on the observed freezing temperature relative to what would be observed in cloud drops. Finally, the equation implies that the droplet freezes at the warmest characteristic freezing temperature out of the set of particles suspended in the droplet. A similar set of assumptions was explored in the analyses by Levine (1950), Vali (1971 and 1994), and Sear (2013), and therefore the above inversion parallels portions of their mathematical analysis of the problem.

The efficacy of Eq. (4) to map raw data (Fig. 1c and d) to the underlying IN spectrum given our experimental constraints was tested using a simulated data set that was constructed from a prescribed IN concentration spectrum. The simulated data set was generated using a discrete event simulator that is similar to the one described in Wright and Petters (2013). Briefly, a random number generator creates two droplet distributions, corresponding to the picodrop and nanodrop regimes: 600 droplets having a mean volume of $400 \pm 20 \mathrm{pL}(D=91.4 \mu \mathrm{m} \pm 33.7 \mu \mathrm{m})$ and 100 droplets having a mean volume of $140 \pm 2.5 \mathrm{~nL}(D=644 \mu \mathrm{m} \pm 168 \mu \mathrm{m})$. These values were selected based on typical distribution parameters for the picodrops and nanodrops, respectively (Sect. 2.1). Each droplet is seeded with a total number of potential IN determined from a Poisson random number generator. The mean number of IN in the drop, i.e. the expectation value for the Poisson random number generator, equalled the maximum synthetic IN concentration multiplied by the volume of the seeded droplet. Each particle is then randomly assigned a characteristic temperature between -10 and $-37^{\circ} \mathrm{C}$ such that the statistics of the distribution followed the prescribed cumulative IN distribution. The freezing temperature of the droplet is determined by selecting the temperature of the most active IN, i.e. the particle having the warmest characteristic temperature in each droplet. The synthetic picodrop and nanodrop populations are then inverted using Eq. (4). Results for 20 simulated experiments are presented in Fig. 2. The first freeze event defines, together with the volume of the droplet, the minimum concentration that can be detected. Since few freeze events are observed at warmer temperatures, there is greater uncertainty in this derived concentration as a result of poor counting statistics. Due to this uncertainty, the warmest $2 \%$ of droplets ( $~ 9$ to 15 droplets for picodrops; $\sim 1$ to 2 droplets for nanodrops) will not be graphed in the data analysis for the real experiments. Overall, the simulation demonstrates that our experimental procedure and inversion will - on average - approximate the true underlying IN spectrum.

\subsection{Example analysis}

Application of Eq. (4) to data necessitates the use of quasimonodispersed droplet populations. For the picodrops shown in Fig. 1a and c, the droplet volumes are polydispersed. To reduce the error introduced by utilizing polydispersed droplets, the range of droplet volumes considered was reduced. Droplets smaller than $250 \mathrm{pL}(D=78.2 \mu \mathrm{m})$ were discarded due to the resolution limit of the optical detection system, and droplets larger than $550 \mathrm{pL}(D=102 \mu \mathrm{m})$ were discarded to keep the dispersion to a minimum. Approximately $50 \%$ of picodrops were within this range and the majority of the discarded droplets were smaller than $250 \mathrm{pL}(D=78.2 \mu \mathrm{m})$. For the nanodrops, the distribution 


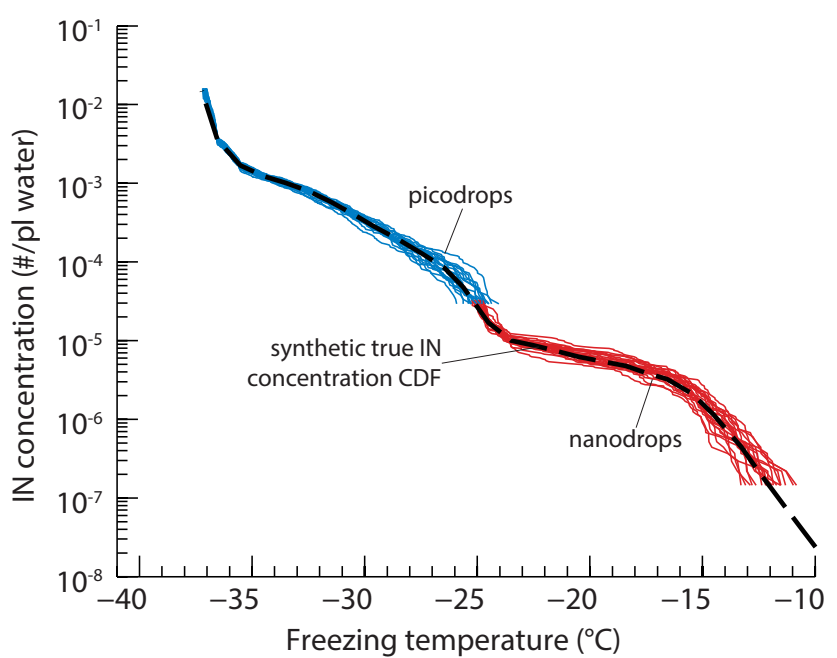

Figure 2. Dashed line: synthetic IN concentration used to generate a randomized instance mimicking the number and size distribution of picodrop and nanodrop experiments shown in Fig. 1c and d. Blue and red lines: inverted IN concentrations for a simulated single experiment using Eq. (4) for picodrop and nanodrop experiments, respectively.

of volumes is smaller and no droplets were discarded. For each sample, the pico- and nanodrop cumulative spectra were independently parsed through Eq. (4) using their respective median drop volumes. The resulting $c_{\mathrm{IN}}(T)$ represents the number of ice nuclei per volume of liquid present in the sample at the given temperature.

The limit of detection of the entire system was determined by characterizing the ice nuclei spectra of ultrapure water. Some small fraction of droplets may freeze at temperatures warmer than the homogeneous limit due to impurities in the water, the squalene, or defects in the glass slides. Figure 3 shows a collection of nine picodrop (unfilled triangles) and four nanodrop (unfilled circles) pure-water experiments. The droplets that froze in these experiments at temperatures colder than $\sim-36^{\circ} \mathrm{C}$ froze at the homogeneous limit, with the spread within each individual experiment's freezing temperatures similar to the uncertainty in the Langham and Mason (1958) measurements of homogeneous freezing. In this region there is evidence of experiment-toexperiment variation in the median freezing temperature. We attribute this variability to imperfect thermal contact between the aluminium dish and the bottom of the cell that had the thermistor embedded inside it (application of thermally conductive paste significantly reduced this variability for subsequent experiments not shown in this article). Figure 1c shows that approximately $10 \%$ of the pure-water droplets froze heterogeneously. This heterogeneous tail corresponds to the change in slope in the grey shaded region shown in Fig. 3. Consequently, IN concentrations less than $10^{-7} \mathrm{pL}^{-1}$ at $T=-20^{\circ} \mathrm{C}$ and $10^{-4} \mathrm{pL}^{-1}$ at $T \sim-36^{\circ} \mathrm{C}$ cannot be detected with this particular set-up and water purity. To iden-

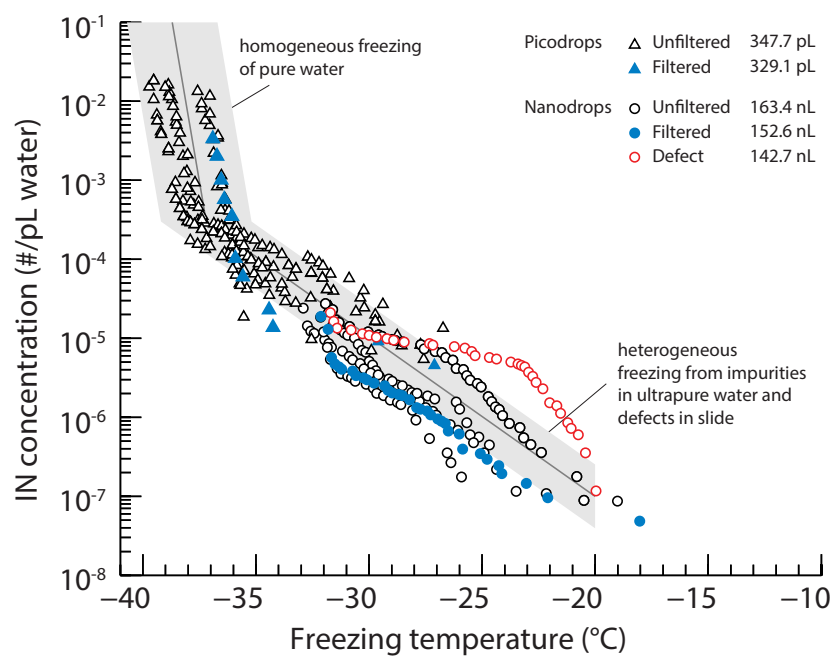

Figure 3. Summary of ice nucleation experiments with ultrapure water. Ice nuclei are expressed as the number of apparent ice nuclei per picolitre of water. Triangles represent picodrop experiments and circles represent nanodrop experiments. Filled symbols indicate filtered/resuspended data. Red circles demonstrate transient noise in the nanodrop experiments in the -20 to $-30^{\circ} \mathrm{C}$ range. Indicated in the top right corner is the average median drop volume for each class of droplets. The grey shaded area indicates an estimate of the experiment-to-experiment variability. The dark grey line corresponds to the average concentration of impurities present in the water.

tify whether the premature freezing is due to impurities in the water or defects in the glass slide, pure water was filtered through a $200 \mathrm{~nm}$ Nuclepore filter ( $\mathrm{mfg}$. Whatman). The material trapped on the filter was then resuspended to produce a $10: 1$ concentration of any particles that would be in the ultrapure water. After accounting for the preconcentration factor, the filtered/resuspended concentrations do not deviate from the reconstructed bulk IN concentrations derived from the unfiltered droplets in the range of temperatures from $\sim-20$ to $-35^{\circ} \mathrm{C}$. This implies that the droplets froze due to impurities in the water. No premature freeze events were observed at temperatures warmer than $\sim-20^{\circ} \mathrm{C}$ within our detection limit, even when the signal from impurities was amplified through filtration. Thus, freeze events at $T>\sim-20^{\circ} \mathrm{C}$ can be unambiguously interpreted to stem from ice nuclei added to the sample. Figure 3 also shows that on occasion a heterogeneous signal elevated over the typical impurity level was observed with the nanodrop method in the temperature range of -20 to $-30^{\circ} \mathrm{C}$ (red circles). We believe that the cause for this transient signal is due to defects in the siliconization of the glass slide. Nonetheless we note that the nanodrop technique can produce reliable data despite the glass defects in cases where the IN concentration is significantly larger than the apparent background concentration derived from the pure-water experiments. However, in cases where the actual IN concentration is low and 

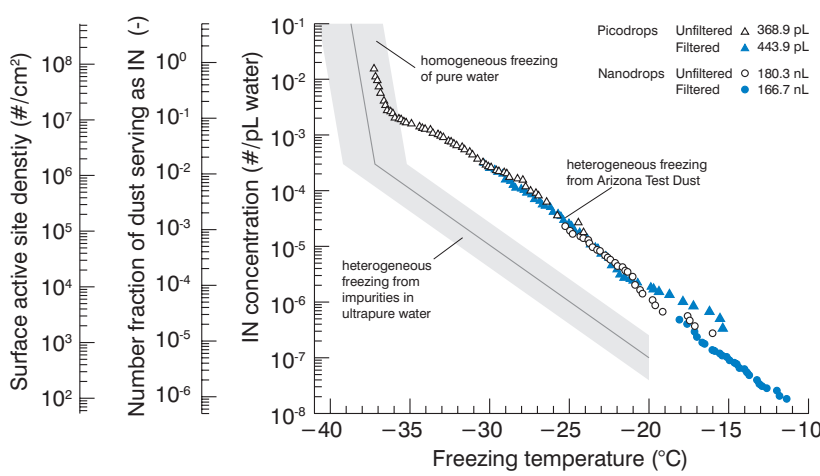

Figure 4. Cumulative ice nuclei spectrum for a suspension of $0.01 \mathrm{wt} \%$ of ATD in ultrapure water. Open and filled symbols correspond to unfiltered and filtered/resuspended experiments, and the numbers in the top right are similar to those in Fig. 3. The filtered/resupspended experiments correspond to a pre-concentration of ATD of $50: 1$. The second axis expresses the data as number fraction of dust serving as IN based on the dust number-to-mass ratio. The third axis expresses the data as IN-active site (INAS) density based on the specific surface area and density of dust provided by the manufacturer.

unknown, nanodrops that froze at temperatures colder than $-20^{\circ} \mathrm{C}$ were considered unreliable and are not reported here. We use the solid line in Fig. 3 to represent an estimate of the average concentration of impurities and the grey shaded area to highlight the experimental variability around that estimate. This corresponds to the overall limit of detection of this method and the purity of the materials used in this study.

The method to infer IN concentration in the liquid was validated by inverting the measured raw data for the $0.01 \mathrm{wt} \%$ ATD suspension (Fig. 1c and d). Both the pico- and nanodrop raw freezing spectra were inverted using Eq. (4). Inferred ice nuclei concentrations per picolitre of liquid are presented in Fig. 4 . There appears to be satisfactory overlap between the picodrops and nanodrops. Combined, this demonstrates that the method is able to quantify IN concentrations ranging between $10^{-8}$ and $10^{-2} \mathrm{pL}^{-1}$ of liquid. We note that we assumed a $100 \%$ recovery for the filtered/resuspended experiments. This assumption is justified since the surface area distribution of the bulk ATD sample peaked at $D>1 \mu \mathrm{m}$, which is significantly larger than the Nuclepore filter pore diameter of $0.2 \mu \mathrm{m}$. It is therefore reasonable to expect that few IN were discarded with the filtrate in this experiment.

The IN number concentration in the liquid was converted to the number fraction of dust particles serving as IN in order to further validate the accuracy of the inferred IN spectrum. For this conversion, the number-to-mass ratio of ATD $\left(2 \times 10^{14}\right.$ particles $\mathrm{kg}^{-1}$ dust; Wright and Petters, 2013) and the mass fraction of dust in the water were used to estimate the average number of ATD particles per picolitre of water. The resulting fractions shown in Fig. 4 (middle ordinate axis) suggest that $\sim 1: 10$ particles serves as IN at $T \sim-36{ }^{\circ} \mathrm{C}$ and $1: 10^{4}$ at $T \sim-20^{\circ} \mathrm{C}$. These fractions are consistent with our previous drop-assay measurements and compare reasonably well with prior continuous-flow diffusion measurements at different temperatures (cf. Fig. 8; Wright and Petters, 2013). Finally, the IN concentration in the liquid was converted to IN-active site (INAS) density:

$\mathrm{INAS}=\frac{c_{\mathrm{IN}}(T) \rho_{\mathrm{ATD}}}{w_{\mathrm{ATD}} \rho_{\mathrm{H}_{2}} \mathrm{O} a_{\mathrm{ATD}}}$,

where $\rho_{\mathrm{H}_{2} \mathrm{O}}=997.1 \mathrm{~kg} \mathrm{~m}^{-3}$ and $\rho_{\mathrm{ATD}}=2650 \mathrm{~kg} \mathrm{~m}^{-3}$ are the bulk densities of water and ATD, respectively; $w_{\mathrm{ATD}}=10^{-4}$ is the mass fraction of the ATD/water suspension, and $a_{\mathrm{ATD}}=4.99 \times 10^{5} \mathrm{~m}^{2} \mathrm{~m}^{-3}$ is the specific surface area of ATD provided by the manufacturer. The derived INAS densities are graphed along the outer ordinal axis of Fig. 4 and are in the same range as the summaries compiled in recent review articles (Hoose and Möhler, 2012; Murray et al., 2012). Based on these results we conclude that the methods using picodrops and nanodrops can reliably quantify the IN concentrations in liquid solutions.

Ambient IN spectra (IN per volume of air) were measured from the SAC solutions on seven different days in April of 2013. Summary statistics for the collections are included in Table 1. SAC sample cumulative IN concentrations were generated in the same way as the ATD spectra, yielding the number of ice nuclei per picolitre of sample water. As an example, data from April 8 are presented in Fig. 5. Ambient IN spectra (defined as the number of $\mathrm{IN} \mathrm{L}^{-1}$ air) were obtained using

$\mathrm{IN}=\frac{\left[c_{\mathrm{IN}}(T)-f c_{\text {impurities }}(T)\right] V_{\mathrm{SAC}}}{Q_{\mathrm{s}} t}$,

where $c_{\text {impurities }}(T)$ denotes the initial concentration of impurities in the SAC water (solid line in Fig. 3), $V_{\mathrm{SAC}}$ is the final water volume in the SAC, $Q_{\mathrm{s}}$ is the sample flow rate through the SAC $\left(12.5 \mathrm{~L} \mathrm{~min}^{-1}\right), f$ is a scaling factor for the impurities due to the water added during SAC operations, and $t$ is the operation time. If no water is added during operation, $f=1$. The scaling factor applied to the SAC data was $f=2$ with the exception of data from 8 April, which used $f=3$ due to its longer collection time necessitating the need for more water to be added.

\section{Results}

Ice nuclei activity for loblolly pine pollen alongside several other pollen species measured previously (Diehl et al., 2002; von Blohn et al., 2005; Pummer et al., 2012) is summarized in Fig. 6. A pollen grain concentration in the suspension of 20 grains $\mu \mathrm{L}^{-1}$ (assuming all particles were grains) was applied to the IN concentration to estimate the number of nucleation sites per pollen grain. Notably, pollen grains do not appear to initiate freezing at temperatures warmer than $-10^{\circ} \mathrm{C}$ for the range of experimental conditions probed in current studies. At $T \sim-10^{\circ} \mathrm{C}$ between $1: 1000$ and $1: 100$ grains are 

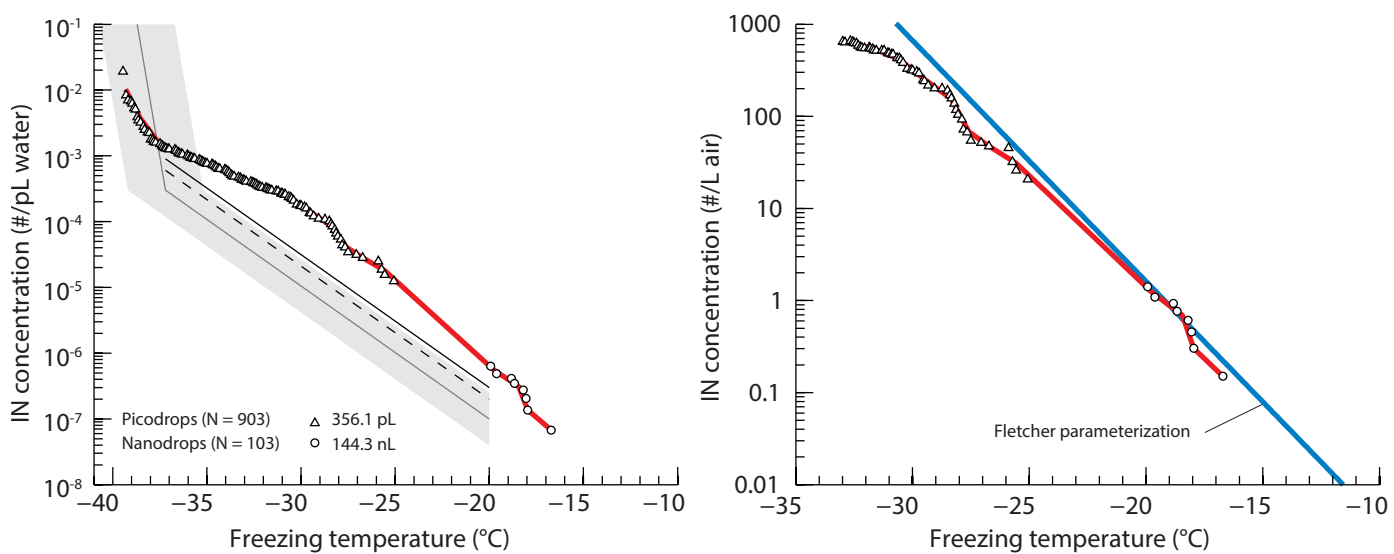

Figure 5. Example cumulative ice nuclei spectra from the SAC on 8 April. Left: analysed in the same manner as shown in Fig. 4 . The grey shaded area corresponds to the background concentration in the water samples shown in Fig. 3. Due to the addition of pure water to the SAC to maintain operation, the noise level was either multiplied by 2 (dashed line) or 3 (thick solid line) depending on the SAC run time. Right: same data as in the left plot but with background concentration (thick solid line in this case) of IN in the ultrapure water subtracted and expressed as IN L ${ }^{-1}$ of air. The red line is the $1^{\circ}$ average of the IN concentration. Overlaid in blue is the Fletcher parameterization using Eq. (7).

able to serve as IN. Birch pollen grains studied by Pummer et al. (2012) and alder pollen grains are expected to nucleate ice (approximately one nucleation site per grain) by $T$ $\sim-18^{\circ} \mathrm{C}$. Pine pollen examined in this study has, on average, one nucleation site per grain at $T \sim-21^{\circ} \mathrm{C}$. Only 20 $30 \%$ of Kentucky blue, Redtop grass, and Lombardy poplar pollen nucleate ice at $T \sim-25^{\circ} \mathrm{C}$. The IN activity of the pine pollen tested is unremarkable and is well within the range of results obtained from the previous studies of different pollen species presented in Fig. 6. Although our results are in good agreement with the IN spectra observed in other pollen species, it is important to note that not all of the particles that induced freezing were necessarily pollen grains. Bacteria, dust, fragments of the pollen grain itself, or other species of pollen present on the harvested male strobili could have served as IN in these experiments. The significant excess of nucleation sites per grain at $T<-22^{\circ} \mathrm{C}$ suggests that there are $\mathrm{IN}$-active particles among the plant debris. The main result from Fig. 6 is that some pollen species are sufficiently IN-active such that each grain can induce ice formation at $T \sim-20^{\circ} \mathrm{C}$. If one were to assume this to be true for all species and in the absence of any multiplication process due to bursting, the maximum contribution of pollen to ice nuclei concentrations at $T \sim-20^{\circ} \mathrm{C}$ is obtained from the pollen grain number concentration in the air.

The evolution of ambient pollen grain concentrations and precipitation through the month of April is presented in Fig. 7. Pollen grain counts were $0.035 \mathrm{~L}^{-1}$ on 2 April and increased to $\sim 0.3-1.7 \mathrm{~L}^{-1}$ for most of the month before dropping below $0.1 \mathrm{~L}^{-1}$ again before the end of the month. The highest pollen grain concentrations observed occurred between 10 and 14 April, followed by a slight decline in pollen grain concentrations that continued through the end of April.

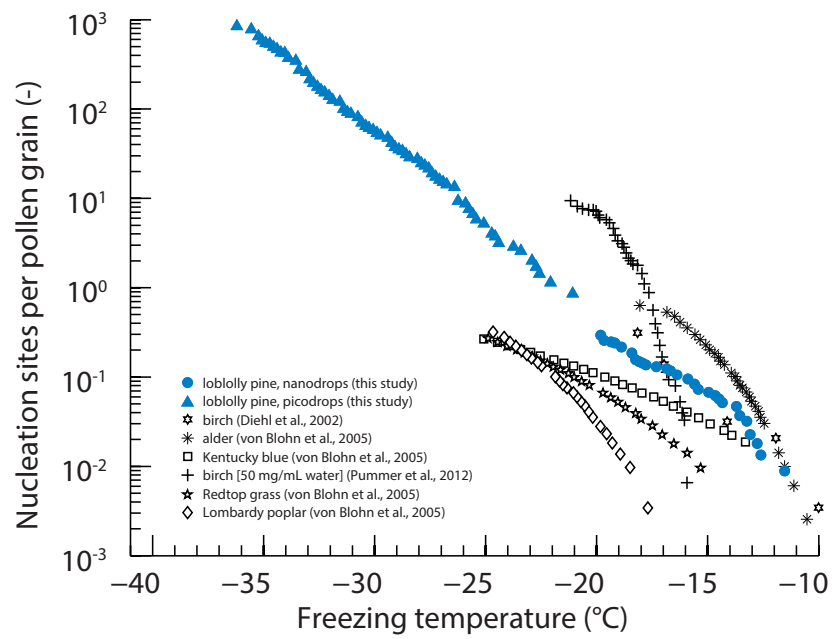

Figure 6. Number of nucleation sites per pollen grain as a function of temperature for various pollen types. Data from this study are shaded in blue. All other data were obtained from Fig. 15 of Murray et al. (2012). References to the original source are provided in the legend.

During the peak of the season most outdoor surfaces were covered by a green slime formed from dry and wet deposition of pollen. Based on these concentrations, and assuming no ice nuclei multiplication process, one would expect that the contribution of pollen to ambient IN concentrations at the time of some of the highest pollen grain concentrations near the surface would be between 1 and $2 \mathrm{~L}^{-1}$ of air at $T=-20^{\circ} \mathrm{C}$.

Significant rain fell on 4, 12, 19, and 28 April. Rain was collected from the events on 12 and 19 April. The rain analysed from 12 April originated from a narrow but intense 


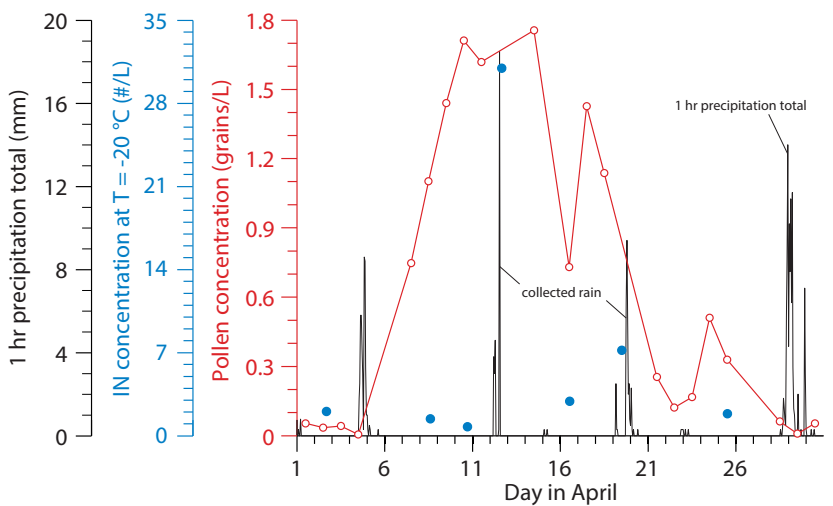

Figure 7. Hourly precipitation (black line), $24 \mathrm{~h}$ pollen grain concentrations (open red circles), and derived IN concentrations at $T=-20^{\circ} \mathrm{C}$ (filled blue circles) for the month of April 2013.

line of showers that passed through Raleigh ahead of a front around 13:00 local time, after a few showers had passed through the area in the early morning. Rain analysed from events A and B on 19 April originated from the stratiform precipitation immediately following the passage of the leading edge of a strong squall line in the early evening (see Fig. 7 and Table 2 for details of rainwater collections). On 19 April the SAC collection preceded the rain event, while on 12 April the SAC collection occurred directly following the shower.

Figure 8 shows the temporal progression of ambient IN spectra derived from the SAC water solutions through the month of April. For the most part, ambient IN concentrations measured from the SAC solutions varied between $\sim 1 \mathrm{~L}^{-1}$ at $T \sim-20^{\circ} \mathrm{C}$ and $\sim 1000 \mathrm{~L}^{-1}$ at $T \sim-33^{\circ} \mathrm{C}$. IN concentrations of $\sim 1 \mathrm{~L}^{-1}$ at $T \sim-20^{\circ} \mathrm{C}$ are broadly consistent with a large set of older data collected in various regions over the continental Northern Hemisphere (see Pruppacher and Klett, 1997, Figs. 9-16 and references therein, pg. 310) as well as with measurements taken at a remote ground site in the Amazon rainforest near Manaus, Brazil (Prenni et al., 2009). The data are also in reasonable agreement with the IN parameterization of Fletcher (1962):

$N_{\mathrm{IN}}=A \exp (B T)$,

where $A=10^{-5} \mathrm{~L}^{-1}$ air and $B=-0.6{ }^{\circ} \mathrm{C}^{-1}$ are empirically determined coefficients, $T$ is the supercooling, and $N_{\text {IN }}$ is the number of active nuclei at temperatures below $T$. This parameterization was developed using data from two types of experiments; the first of which used visual estimation of ice crystal counts in a saturated environment using a slow cooling rate, while the other used visual or aided visual counts of ice crystals at fixed temperatures. We note that the Fletcher parameterization predicts $N_{\mathrm{IN}} \sim 1 \mathrm{~L}^{-1}$ at $T=-20^{\circ} \mathrm{C}$ and $N_{\mathrm{IN}} \sim 650 \mathrm{~L}^{-1}$ at $T=-30^{\circ} \mathrm{C}$. Most of the ambient IN spectra shown in Fig. 8 are in excellent agreement with the parameterization, including the slope of the temperature dependence. Nonetheless, the shape of the spectra does not always
Table 2. Summary of rainwater collection times

\begin{tabular}{lccr}
\hline Rain event & Time out & Time in & $\begin{array}{r}\text { Volume } \\
(\mathrm{mL})\end{array}$ \\
\hline 12 April & $12: 58$ & $13: 25$ & 430 \\
19 April A & $19: 04$ & $20: 19$ & 250 \\
19 April B & $20: 19$ & $21: 41$ & 75 \\
\hline
\end{tabular}

follow a strict exponential increase with decreasing temperature. For example, the spectrum on 12 April shows a sharp increase in $N_{\text {IN }}$ at $T \sim-12{ }^{\circ} \mathrm{C}$ and approaches $30 \mathrm{~L}^{-1}$ at $T \sim-20^{\circ} \mathrm{C}$, followed by a relatively small increase in IN concentrations at lower temperatures. This indicates a distinct mode of more active IN that is not present in the other samples.

IN spectra measured in rainwater samples are shown in Fig. 9. IN concentrations varied between $10^{-7} \mathrm{pL}^{-1}$ at $T \sim-15^{\circ} \mathrm{C}$ (no. of IN per picolitre of rainwater) and $10^{-2} \mathrm{pL}^{-1}$ at $T \sim-38^{\circ} \mathrm{C}$. For reference, a 10 and $20 \mu \mathrm{m} \mathrm{di}-$ ameter cloud drop corresponds to a water volume of $\sim 0.5$ and $4 \mathrm{pL}$, respectively. We therefore interpret the direct observation of $10^{-8} \mathrm{IN} \mathrm{pL}^{-1}$ as being equivalent to $\sim 1: 10^{8}$ cloud drops containing an IN that is able to induce freezing at $T=-12{ }^{\circ} \mathrm{C}$. If one further assumes a cloud droplet number concentration between 100 and $1000 \mathrm{~cm}^{-3}$, it is possible to derive corresponding approximate effective IN concentrations between 0.001 and $0.01 \mathrm{~L}^{-1}$ of air. Although these conversions are highly approximate, the measured IN concentrations derived from the rainwater measurements are in broad agreement with those derived from the SAC sampler. Conspicuously, with the exception of the SAC-derived data from 12 April, IN concentrations across samples at $T>-15^{\circ} \mathrm{C}$ did not exceed $1 \mathrm{~L}^{-1}$.

As demonstrated earlier (Fig. 6), generic pollen grains contain at least one nucleation site per grain between -15 and $-25{ }^{\circ} \mathrm{C}$. Furthermore, the contribution of PBAP to IN concentrations relative to that of mineral and dust particles is expected to be larger at $T>-20^{\circ} \mathrm{C}$. Therefore the main area of interest here is the concentration of IN in the $-10<T<-20^{\circ} \mathrm{C}$ range and how it fluctuated with changes in ambient pollen grain concentrations. On six out of the seven ambient collection days, IN concentrations between -10 and $-20^{\circ} \mathrm{C}$ ranged between 0.01 and $10 \mathrm{~L}^{-1}$. Ambient pollen grain concentrations on these days ranged from as high as $1.7 \mathrm{~L}^{-1}$ to as low as $0.035 \mathrm{~L}^{-1}$. Only one collection day, 12 April, saw IN concentrations in this temperature range fluctuating between $\sim 1$ and $30 \mathrm{~L}^{-1}$. This day saw the second-highest ambient pollen grain concentration (on a day that SAC sampling took place) at $1.6 \mathrm{~L}^{-1}$, and was also the only day on which ambient IN collection took place after measurable rain fell on the same day. The warmest temperature at which an IN concentration greater than $1 \mathrm{~L}^{-1}$ of air is observed varies between -12 and $-21^{\circ} \mathrm{C}$ 


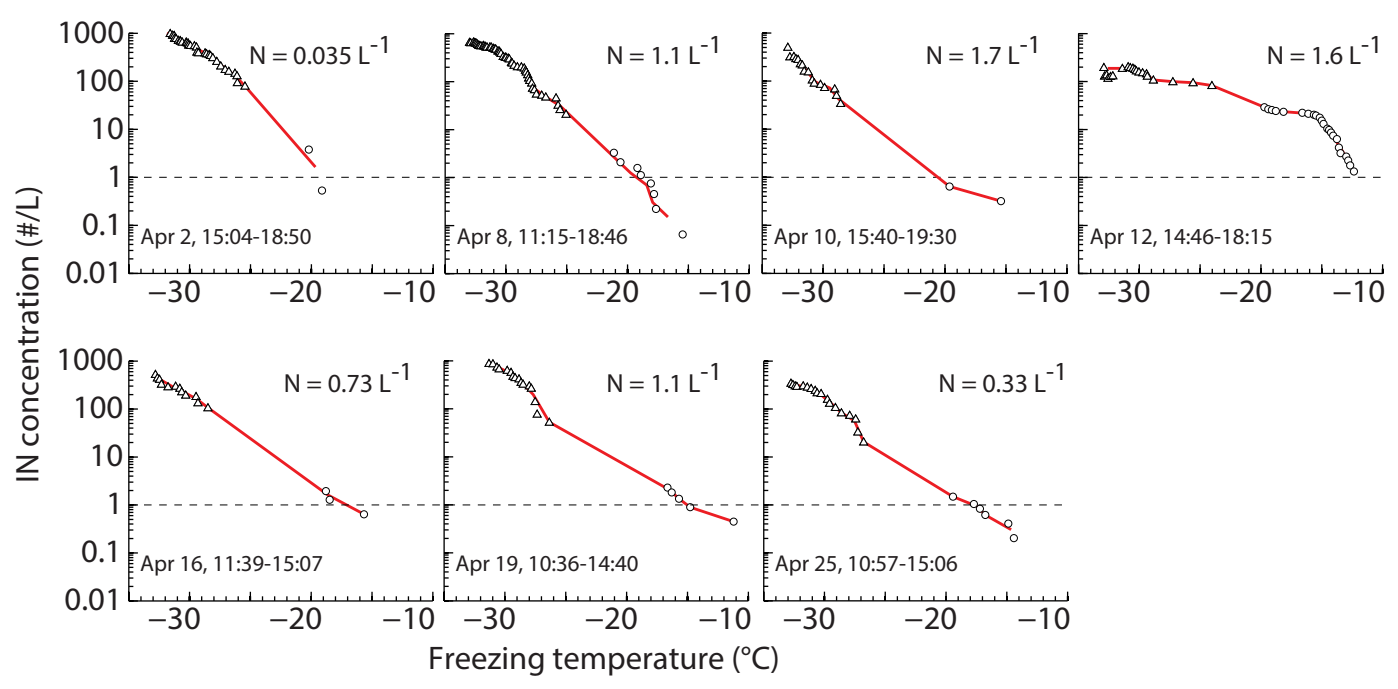

Figure 8. Summary of ambient air ice nuclei data during the April pollen season. Number of IN per litre of air is obtained from the SAC. The label in the bottom left of each plot indicates the date and time the sample was collected. The $N$ value in the top right corner denotes the average number of pollen grains per litre of air during the closest $24 \mathrm{~h}$ period during which the NC Department of Air Quality pollen counts coincided with sample collection. The symbols corresponding to picodrops and nanodrops are identical to those in Fig. 3 . The red lines are the $1^{\circ}$ averages of the IN concentrations. The horizontal dashed line corresponds to IN concentrations of $1 \mathrm{~L}^{-1}$ and is added to guide the eye.

throughout the season; however there is no clear correlation between this value and the pollen grain concentration. The estimated IN in the rainwater samples ranged between $10^{-7}$ and $10^{-6} \mathrm{pL}^{-1}$ of water (or $\sim 0.01$ to $0.1 \mathrm{~L}^{-1}$ of air) in the $-10<T<-20^{\circ} \mathrm{C}$ range.

\section{Discussion}

Using the drop-freezing method for quantitative measurements from SAC solutions and rainwater has several advantages and limitations. The main advantages of the technique are its ability to infer a complete ice nucleation spectrum (e.g. Fig. 3) with relatively few experimental runs and its ability to more closely mimic the timescales and cooling rates that are typically encountered in the atmosphere. By combining many tens to hundreds of potential IN particles inside a single droplet the method can effectively detect low IN concentrations toward the warm end of the spectrum. Furthermore, supermicron size particles can be collected with the SAC and analysed in the cold-stage freezing assay. The ability to sample supermicron particles is desirable since particle number concentrations with $D>0.5 \mu \mathrm{m}$ have been shown to correlate with IN (Georgi and Kleinjung, 1968) and are currently used to parameterize IN in global models (DeMott et al., 2010).

Inferring ambient IN concentrations from the SAC solutions and the drop-freezing assay method does come with some key limitations. The aerosol collection efficiency of the SAC decreases significantly when the particle diameters drop below $\sim 0.2 \mu \mathrm{m}$ (Willeke et al., 1998). If there is a significant IN contribution from these smaller particles, the measurements contained within this study will underestimate IN concentrations. During measurements the aqueous matrix surrounding the ice nucleus will be identical for each SAC-derived IN concentration experiment. However, this solution may differ from the composition and concentrations within the solutions generated within clouds and in rain drops that transport the IN to the surface. Dissolved compounds found in rainwater solutions, e.g. nitrate and sulfate salts and/or various organic compounds, could lead to freezing point depression. The magnitude of the freezing point depression is directly related to the water activity of the solution (e.g. Koehler et al., 2006). Water activity is approaching unity at the solute concentrations found during and after cloud droplet activation (Petters et al., 2009), and thus the total freezing point depression is expected to be small. If concentrated solutions are used for analysis, it may be possible to measure the bulk water activity and apply a wateractivity-based model of ice nucleation to correct for this effect (Knopf and Alpert, 2013). Further changes may occur to the IN pool in the time between sample collection and experimental measurements. For example, particles may coagulate in solution and obscure (or perhaps generate) active sites along the particle-particle interface. During measurements particles inside the drops can migrate to the water-oil interface via Brownian motion or gravitational settling and induce contact freezing from the inside. Inside-out contact nucleation has been hypothesized as a mechanism whereby the nucleation rate increases through surface crystallization when the IN moves into contact with the edge of the water droplet (Shaw et al., 2005; Durant and Shaw, 2005). It is 


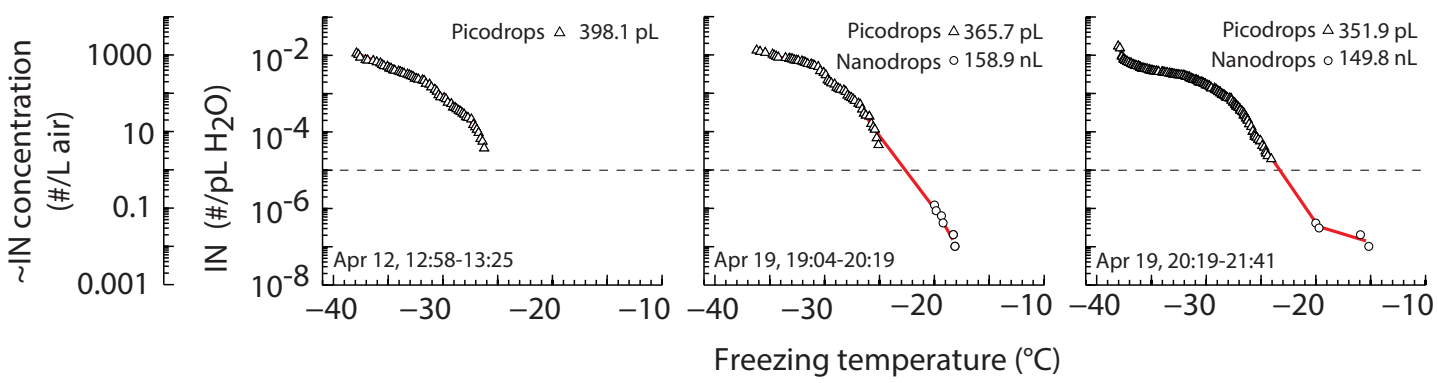

Figure 9. The primary $y$ axis gives the number of ice nuclei per picolitre of water measured in precipitation samples. The secondary $y$ axis roughly approximates IN concentrations per litre of air, assuming that $1 \mathrm{pL} \sim 1$ cloud droplet and a cloud droplet number concentration of $100 \mathrm{~cm}^{-3}$. The label on the bottom left of the plot indicates the date and time during which the sample was collected. The horizontal dashed line corresponds to IN concentrations of $1 \mathrm{~L}^{-1}$ and is added to guide the eye.

not possible to distinguish between immersion and inside-out contact freezing modes of ice nucleation within our current experimental set-up when performing single-run measurements. Evidence that this phenomenon could be occurring in our set-up has been documented in the past with experiments that included repeated freeze-thaw cycles (Wright and Petters, 2013; Wright et al., 2013). Since particles that induce freezing by the inside-out contact mode do so at a warmer temperature than identical particles that induce freezing by the immersion mode, contributions from the contact mechanism may lead to our results having a slight warm bias in the spectra (Durant and Shaw, 2005).

Unambiguously interpreting results from rainwater samples is also difficult. Undoubtedly the rain drop collects some aerosol on its path through the column. Thus not all IN in the rainwater contribute to the IN signal at cloud level. In the atmosphere some IN processes may occur via preactivation of the aerosol (Roberts and Hallet, 1968; Knopf and Koop, 2006). It is possible that the IN activity of some of the nuclei can be irreversibly lost when the IN is warmed significantly above zero Celsius. Finally, mapping between IN concentration in the liquid sample and the fraction of cloud drops that carry an IN requires assumptions about the average liquid water content of a single cloud. The quantitative application of these data to cloud ice processes will require careful analysis of these factors.

The above data are suitable to use to formulate some general conclusions. Assuming that each pollen grain in Raleigh serves as an IN would imply that during most sampling days the IN concentrations at $-20^{\circ} \mathrm{C}$ could be explained solely by pollen because typical IN concentrations at $-20^{\circ} \mathrm{C}$ and pollen grain concentrations were both $1 \mathrm{~L}^{-1}$ air. However, IN concentrations at this temperature were $1 \mathrm{~L}^{-1}$ on 2 April while pollen grain counts were negligible, and $\sim 30 \mathrm{~L}^{-1}$ on 12 April when pollen grain counts were $1.6 \mathrm{~L}^{-1}$. Furthermore, it is unclear as to whether each pollen grain in the sample has IN activity that is similar to those of the species presented in Fig. 6. It is likely that an ambient sample comprising a highly diverse population of pollen will contain some species that are IN-inactive. We therefore believe that pollen and pollen-derived particles only accounted for a fraction of the observed IN concentration, with the remainder being controlled by other natural and/or anthropogenic sources.

Pummer et al. (2012) acknowledge that pollen is typically rejected as a significant source of ambient IN concentrations. Emissions are episodic, concentrations are typically less than $1 \mathrm{~L}^{-1}$, and they strongly decrease with height so that only a few grains are entrained in updrafts that penetrate the mixedphase cloud regime. However, Pummer et al. (2012) suggest that the impact of pollen on atmospheric clouds might have been underestimated due to the ejection of IN-active macromolecules from the pollen grain. Our results, restricted to a single ecosystem with limited variation in meteorological conditions, are inconsistent with this hypothesis. For pollen or pollen-derived IN to be important in cloud processes they must contribute significantly to IN number concentrations beyond background levels. At $T \sim-20^{\circ} \mathrm{C}$ a large number of observations around the world suggest that IN concentrations range between 0.5 and $\sim 30 \mathrm{~L}^{-1}$ (Mossop, 1963; DeMott et al., 2010). Our values measured at the beginning and end of April, corresponding to before and after the peak pollen season, are well within that range. At ambient pollen grain concentrations of $1 \mathrm{~L}^{-1}$ and anticipating the release of tens to hundreds of macromolecules per grain, one would estimate maximum IN concentrations of $100-1000 \mathrm{~L}^{-1}$ at $T \sim-20^{\circ} \mathrm{C}$. Our measurements show that at the peak of the pollen season near a source of pollen there appears to be no such increase in IN concentrations. The absence of an elevated IN signal near a strong source at the peak of the pollen season underscores the fact that pollen emissions were likely too small to dramatically augment atmospheric IN spectra during the 2013 pollen season in Raleigh, NC. Similar methods need to be applied over extended time periods to further validate this finding and to account for the potential influence of other uncontrolled factors.

Some indication for pollen's minimal contribution to IN concentrations also comes from the 19 April rainwater analyses. The IN in the rainwater samples presumably comprises 
a mixture of particles emanating from the cloud drops that coalesced with or accreted onto the settling hydrometeor and particles collected from the column via Brownian or inertial scavenging. Ambient IN concentrations estimated from the rainwater data suggest that IN concentrations at $T=-20^{\circ} \mathrm{C}$ are $0.05-0.1 \mathrm{~L}^{-1}$ air (Fig. 9), approximately 1 order of magnitude lower than ambient concentrations at ground level. Given the large uncertainties due to the assumptions made in the conversion from rainwater to ambient concentrations we believe that ground-based and precipitation-derived ambient IN concentrations are broadly self-consistent. Despite these uncertainties we believe that the data are sufficiently robust to exclude the possibility of a large abundance of IN that was present at cloud level or scavenged from the air column.

We note that both the SAC samples and the rainwater samples potentially favour the extraction of macromolecules from the pollen grains since they are immersed in a bulk liquid. Thus freshly emitted grains that did not undergo wetting and drying cycles or come in contact with cloud or rainwater prior to impaction in the SAC would still have the possibility to seed the SAC solution with copious amounts of IN. We point out that the lower size cut of $0.2 \mu \mathrm{m}$ of the SAC sampler does not apply to macromolecules leached from the pollen grain in the SAC solution. Similarly, pollen captured in the rainwater would have been subjected to atmospheric processing prior to the measurement. Without further information we would expect that more IN-active macromolecules are present in the rainwater and SAC water relative to macromolecule counts expected from pollen grain bursting in the atmosphere alone, without the subsequent immersion step into a bulk water phase.

We note that our results only imply that, within the context of the ecosystem surrounding this study locale, it is unlikely that an ice nuclei multiplication process enhances the contributions of whole pollen grains to ice nuclei populations. No inferences can be made about the importance of pollen ice nuclei (or biological ice nuclei) in either cloud processes or bioparticle dispersal processes. Specifically, the concentration levels that are needed to perturb clouds via ice phase processes are unknown, and those levels likely depend on cloud microstructure, cloud lifetime, and cloud temperatures. The ice nucleation activity of pollen (and bioparticles) may or may not affect their distance travelled and their viability after long-range transport and cloud processing (Williams, 2013). Most importantly, the pollen or bioparticle flux must be characterized to fully assess feedbacks between the biosphere and atmosphere in bio-precipitation processes.

The 12 April data show that ice nuclei concentrations increased $\sim 30$-fold at $T \sim-20^{\circ} \mathrm{C}$ relative to background concentrations directly after the precipitation event. These findings are consistent with previous observations of the precipitation trigger (Huffman et al., 2013; Prenni et al., 2013). For example, Prenni et al. (2013) observed that IN concentrations were enhanced by an order of magnitude after rainfall with a concomitant increase in fluorescent particles. The in- crease in fluorescent particles combined with DNA analysis suggests that the enhancement was driven by biological particles (Huffmann et al., 2013). The rainfall-induced IN burst observed in our study has an onset freezing temperature of $-12{ }^{\circ} \mathrm{C}$ (Fig. 8) and concentrations are significantly higher than those observed by Prenni et al. (2013) at $T=-15^{\circ} \mathrm{C}$ (cf. their Table 1). Similarly, Huffman et al. (2013) observed lower IN concentrations $\sim 0.6 \mathrm{~L}^{-1}$ at $-12{ }^{\circ} \mathrm{C}$ for particles in the size range of $\sim 2$ to $5 \mu \mathrm{m}$.

We argue that the observed onset freezing temperature of $-12{ }^{\circ} \mathrm{C}$ (Fig. 8) points to a biological origin of the IN. First, non-biological sources such as mineral dust, black carbon, and volcanic ash become inefficient IN on a per surface area basis at $T>-20^{\circ} \mathrm{C}$ (Murray et al., 2012). Conversely, efficient IN that induce freezing at $T>-15^{\circ} \mathrm{C}$ are a select species from the bacteria (Maki et al., 1974), lichen (Kieft, 1988), pollen (Diehl et al., 2002), and fungi (Richard et al., 1996; Huffmann et al., 2013) groups. Second, the humidityand wind-speed-related mechanisms that lead to bioaerosol emission during rain storms (e.g. Webster et al., 1984; Pasanen et al., 1991; Paul et al., 2004) are likely applicable in any densely populated ecosystem. Thus, although we do not have direct measurements of IN composition, we believe that the release of biologically derived particles (presumably the sum over all sources and not just pollen) are a plausible explanation for the IN burst observed on 12 April.

The absolute concentrations of the rain-induced IN burst reported here are significantly larger than the values reported by Prenni et al. (2013), IN $\sim 20 \mathrm{~L}^{-1}$ vs. $0.2 \mathrm{~L}^{-1}$ at $T=-15^{\circ} \mathrm{C}$. There are several possible explanations for this difference. The continuous-flow diffusion method used in Prenni et al. (2013) requires the use of an impactor that removes particles with diameters greater than $1.5 \mu \mathrm{m}$. Many fungal spores and pollen grains exceed this dimension. The most efficient IN detected by Huffman et al. (2013) were in the $\sim 2$ to $5 \mu \mathrm{m}$ range and thus would be undersampled by the continuous-flow diffusion method. Since large particles are effectively sampled by the SAC, they may have been detected in this study but missed during BEACHON-RoMBAS. In addition, both season (spring versus summer) and climate zone (temperate and humid versus semi-arid) differed. Thus differences in vegetation may explain the significantly larger release observed in this study. A key implication of the foregoing argument is the importance of the rain-splash release in the Amazon rainforest. Previous observations have suggested that IN at $T>-20^{\circ} \mathrm{C}$ are biological in origin (Prenni et al., 2009). If the rainfall-triggered bursts are larger in rainy climates and underestimated by continuous-flow diffusion methods, then the release of cloud-forming particles (Pöschl et al., 2010; Huffman et al., 2013) may be underestimated. 


\section{Conclusions}

Ambient IN spectra were measured using a swirling aerosol collector combined with a drop-freezing assay. Measurements were made approximately twice per week to capture the evolution of the IN spectra through the peak of the 2013 pollen season. No clear correlation between ambient pollen grain concentrations and ambient IN concentrations was observed. Ice nuclei spectra for loblolly pine pollen, a dominant source of tree pollen in the region, were examined and ice nuclei activity was unremarkable and comparable with spectra of other pollen species reported in previous studies. Based on the known ice nuclei activity of pollen-derived IN, ambient pollen grain concentrations, and the evolution of the IN spectra through the season, we conclude that ice nuclei multiplication from the bursting of pollen grains is unlikely a significant source of IN over North Carolina, USA. Episodic emissions, low number concentrations even at the peak of the season $\left(\sim 1 \mathrm{~L}^{-1}\right)$, strong vertical gradients, and relatively cold freezing temperatures for many pollen types $\left(T \sim-20^{\circ} \mathrm{C}\right)$ suggest that the contribution of pollen relative to the background IN signal is small and likely negligible on a global scale. A serendipitous measurement of an IN spectra on 12 April 2013 provided evidence for a rain-induced IN burst with peak concentration of $\sim 30 \mathrm{~L}^{-1}$ at $T \sim-20^{\circ} \mathrm{C}$. We presume that these particles are biological primarily due to the well-studied release mechanism of bioaerosol during rain and the warm onset temperature of freezing at $T \sim-12^{\circ} \mathrm{C}$. The magnitude of the IN burst was significantly larger than previously observed.
Acknowledgements. This research was funded by the National Science Foundation (NSF) award NSF-AGS 1010851. We thank C. Osburn for providing us with ultrapure water. We thank Claire Williams and Gabor Vali for useful discussions about the biology of pollen and the drop-freezing method, respectively.

Edited by: R. Krejci 


\section{Appendix A: Particle collection and sampling efficiencies}

The inlet piece of the swirling aerosol collector (SAC) includes a $90^{\circ}$ bend. The inlet has an inside diameter of $8 \mathrm{~mm}$ and is approximately $1 \mathrm{~cm}$ from the entrance to the beginning of the bend. No other sampling line was added.

To assess particle losses in the inlet we calculated the fraction of particles that stay in the streamlines of the airflow through the bend as a function of particle size. Calculations assumed a flow rate of $12.5 \mathrm{~L} \mathrm{~min}^{-1}$. This corresponds to a flow velocity of $4.14 \mathrm{~m} \mathrm{~s}^{-1}$ and a Reynolds number of $\sim 2210$. The Reynolds number indicates the flow is only marginally laminar, and therefore we report fractional penetration assuming the worst-case scenario of turbulent flow through the bend (Baron and Willike, 2001). Results are shown in Fig. A1 and demonstrate that particles with $D>10 \mu \mathrm{m}$ are expected to impact the inlet wall. This calculation agrees with previously reported collection efficiencies, extending up to $2 \mu \mathrm{m}$ particles (Willeke et al., 1998), and is in close agreement with results performed using the Particle Loss Calculator software (von der Wieden et al., 2009).

Investigated particle size ranges fall into two categories. Particles from burst pollen grains are in the range of $\sim 0.2$ to $5 \mu \mathrm{m}$ (Suphioglu et al., 1992; Taylor et al., 2002) while whole airborne pollen grains can reach sizes up to $100 \mu \mathrm{m}$, with typical sizes ranging between 30 and $70 \mu \mathrm{m}$ for pine tree pollen (Erdtman, 1952; Di-Giovanni et al., 1995). The calculations show that whole pollen grains will leave the airflow and impact on the wall of the inlet. Depending on humidity, particle wetness, and hardness, particles will either stick to or bounce off the wall (Juozaitis et al., 1994; Kannosto et al., 2013). Bounce and blow-off fractions for ragweed pollen on non-greased impactor stages are 30-60\% (Riediker et al., 2000). In the case of particle bounce, it would be unrealistic for the particles to move against the airflow and leave the aerosol sampler. Therefore, any particles that do bounce are expected to enter the instrument for collection.

As mentioned in Sect. 2.1, "Experimental procedures", the collection vessel needs to be refilled up to $\sim 20 \mathrm{~mL}$ every hour. When assembling the components of the sampler, stopcock grease was employed to seal the joints. To ensure that the grease would not contaminate the sample water, we chose not to disassemble the instrument to refill the collection vessel. Instead we sprayed ultrapure water through the inlet and let the vacuum system pull the water through the orifices $(D=680 \mu \mathrm{m})$ and into the collection vessel. This procedure has the added benefit of washing any particles that stuck to the glass wall into the sample water. We note that this washing was not performed after the last hour of measurement and no quantitative assessment of the collection efficiency for $D>10 \mu \mathrm{m}$ particles was performed.

Another potential source of reduced capture efficiency of particles is non-isokinetic sampling. Acceleration of the flow into the inlet may result in large particles being diverted

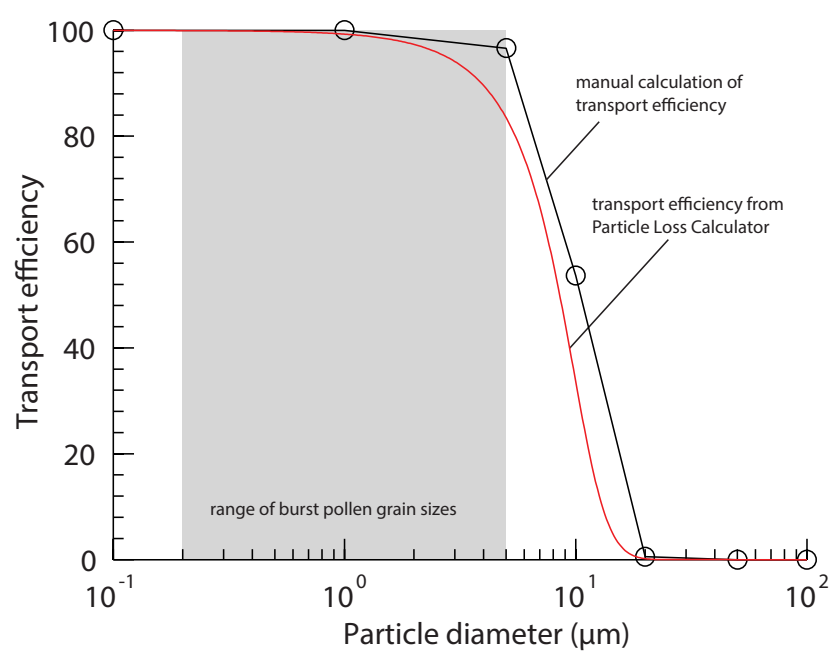

Figure A1. Particle transport efficiency as a function of particle size through the inlet of the SKC swirling aerosol collector. The black line is the calculated transport efficiency using Eq. (8)-(67) from Baron and Willeke (2001). The red line is the transport efficiency found using the Particle Loss Calculator (von der Weiden et al., 2009). The shaded grey area is range of particle diameters for burst pollen grains (Suphiopglu et al., 1992; Taylor et al., 2002).

from the flow streamlines. However, flow velocities are small $\left(\sim 4 \mathrm{~m} \mathrm{~s}^{-1}\right)$, and centre streamlines are not affected.

In summary, the collection efficiency for $D>10 \mu \mathrm{m}$ particles is less than $100 \%$, but likely larger than $50 \%$ due to the bounce and blow-off as well as the wash-off mechanisms. Most importantly, the calculations in Fig. A1 demonstrate that pollen fragments suspected to be responsible for significantly impacting ice nuclei concentrations are small enough to be sampled with nearly $100 \%$ efficiency. Any enhancement of ice nuclei due to the cytoplasmic debris that can be separated from the pollen grain as micron- and submicronsized starch granules should have been observed with our method. Furthermore, the ice nuclei emitted from the rain trigger reported previously have $D<10 \mu \mathrm{m}$ (Huffman et al., 2013) and are also effectively sampled with the impinging sampler. 


\section{References}

Andreae, M. O. and Rosenfeld, D.: Aerosol-cloudprecipitation interactions. Part 1 . The nature and sources of cloud-active aerosols, Earth-Sci. Rev., 89, 13-41, doi:10.1016/j.earscirev.2008.03.001, 2008.

Ariya, P. A., Sun, J., Eltouny, N. A., Hudson, E. D., Hayes, C. T., and Kos, G.: Physical and chemical characterization of bioaerosols - Implications for nucleation processes, Int. Rev. Phys. Chem., 28, 1-32, doi:10.1080/01442350802597438, 2009.

Augustin, S., Wex, H., Niedermeier, D., Pummer, B., Grothe, H., Hartmann, S., Tomsche, L., Clauss, T., Voigtländer, J., Ignatius, K., and Stratmann, F.: Immersion freezing of birch pollen washing water, Atmos. Chem. Phys., 13, 10989-11003, doi:10.5194/acp-13-10989-2013, 2013.

Baron, P. A. and Willeke, K.: Aerosol Measurement, Principles, Techniques, and Applications, 2nd Edn., Wiley-Interscience, New York., 2001.

Campbell, I. D., Mcdonald, K., Flannigan, M. D., and Kringayark, J.: Long-distance transport of pollen into the Arctic, Nature, 399, 29-30, 1999.

Chernoff, D. I. and Bertram, A. K.: Effects of sulfate coatings on the ice nucleation properties of a biological ice nucleus and several types of minerals, J. Geophys. Res., 115, D20205, doi:10.1029/2010JD014254, 2010.

Christner, B. C., Cai, R., Morris, C. E., McCarter, K. S., Foreman, C. M., Skidmore, M. L., Montross, S. N., and Sands, D. C.: Geographic, seasonal, and precipitation chemistry influence on the abundance and activity of biological ice nucleators in rain and snow, P. Natl. Acad. Sci. USA, 105, 18854-188549, doi:10.1073/pnas.0809816105, 2008a.

Christner, B. C., Morris, C. E., Foreman, C. M., Cai, R., and Sands, D. C.: Ubiquity of biological ice nucleators in snowfall, Science, 319, 1214, 2008b.

DeMott, P. J., Prenni, A. J., Liu, X., Kreidenweis, S. M., Petters, M. D., Twohy, C. H., Richardson, M. S., Eidhammer, T., and Rogers, D. C.: Predicting global atmospheric ice nuclei distributions and their impacts on climate., P. Natl. Acad. Sci. USA, 107, 1121722, doi:10.1073/pnas.0910818107, 2010.

Després, V. R., Huffman, A., J., Burrows, S. M., Hoose, C., Safatov, A. S., Buryak, G., Fröhlich-Nowoisky, J., Elbert, W., Andreae, M. O., Pöschl, U., and Jaenicke, R.: Primary biological aerosol particles in the atmosphere: a review, Tellus B, 64, 15598, doi:10.3402/tellusb.v64i0.15598, 2012.

Di-Giovanni, F., Kevan, P. G., and Nasr, M. E.: The variability in settling velocities of some pollen and spores, Grana, 34, 39-44, doi:10.1080/00173139509429031, 1995.

Diehl, K., Matthias-Maser, S., Jaenicke, R., and Mitra, S. K.: The ice nucleating ability of pollen?: Part II. Laboratory studies in immersion and contact freezing modes, Atmos. Res., 61, 125$133,2002$.

Durant, A. J. and Shaw, R. A.: Evaporation freezing by contact nucleation inside-out, Geophys. Res. Lett., 32, L20814, doi:10.1029/2005GL024175, 2005.

Elander, J. C. and Gebhard, D. E.: Pre-greased collecting rod assembly for pollen and fungal spore sampling and method of making it, US Patent 6,696,288, Issued 2004.

Erdtman, G.: Pollen morphology and plant taxonomy; an introduction to palynology, Chronica Botanica Co., Waltham, Mass., 1952.
Fletcher, N. H.: The Physics of Rainclouds, Cambridge University Press, Cambridge, Great Britain, 1962.

Georgi, H. W. and Kleinjung, J.: Relations between the chemical composition of aerosols and the concentration of natural ice nuclei, Journal de Recherches Atmospheriques, 3, 145-156, 1968.

Gregory, P. H.: Distribution of airborne pollen and spores and their long distance transport, Pure Appl. Geophys. PAGEOPH, 116, 309-315, doi:10.1007/BF01636888, 1978.

Grote, M., Valenta, R., and Reichelt, R.: Abortive pollen germination: A mechanism of allergen release in birch, alder, and hazel revealed by immunogold electron microscopy, J. Allergy Clin. Immun., 111, 1017-1023, doi:10.1067/mai.2003.1452, 2003.

Hoose, C. and Möhler, O.: Heterogeneous ice nucleation on atmospheric aerosols: a review of results from laboratory experiments, Atmos. Chem. Phys., 12, 9817-9854, doi:10.5194/acp-12-98172012, 2012.

Huffman, J. A., Prenni, A. J., DeMott, P. J., Pöhlker, C., Mason, R. H., Robinson, N. H., Fröhlich-Nowoisky, J., Tobo, Y., Després, V. R., Garcia, E., Gochis, D. J., Harris, E., Müller-Germann, I., Ruzene, C., Schmer, B., Sinha, B., Day, D. A., Andreae, M. O., Jimenez, J. L., Gallagher, M., Kreidenweis, S. M., Bertram, A. K., and Pöschl, U.: High concentrations of biological aerosol particles and ice nuclei during and after rain, Atmos. Chem. Phys., 13, 6151-6164, doi:10.5194/acp-13-6151-2013, 2013.

Juozaitis, A., Willeke, K., Grinshpun, S. A., and Donnelly, J.: Impaction onto a Glass Slide or Agar versus Impingement into a Liquid for the Collection and Recovery of Airborne Microorganisms, Appl. Environ. Microb., 60, 861-70, 1994.

Kannosto, J., Yli-Pirilä, P., Li-Qing, H., Leskinen, J., Jokiniemi, J., Mäkelä, J. M., Joutsensaari, J., Laaksonen, A., Worsnop, D., Keskinen, J., and Virtanen, A.: Bounce characteristics of $\alpha$-pinenederived SOA particles with implications to physical phase, Boreal Environ. Res., 18, 329-340, 2013.

Kieft, T. L.: Ice Nucleation Activity in Lichens, Appl. Environ. Microb., 54, 1678-1681, 1988.

Knopf, D. A. and Alpert, P. A.: A water activity based model of heterogeneous ice nucleation kinetics for freezing of water and aqueous solution droplets, Faraday Discuss., doi:10.1039/c3fd00035d, 2013.

Knopf, D. A. and Koop, T.: Heterogeneous nucleation of ice on surrogates of mineral dust, J. Geophys. Res., 111, D12201, doi:10.1029/2005JD006894, 2006.

Koehler, K. A., Kreidenweis, S. M., DeMott, P. J., Prenni, A. J., Carrico, C. M., Ervens, B., and Feingold, G.: Water activity and activation diameters from hygroscopicity data - Part II: Application to organic species, Atmos. Chem. Phys., 6, 795-809, doi:10.5194/acp-6-795-2006, 2006.

Koehler, K. A., Kreidenweis, S. M., DeMott, P. J., Petters, M. D., Prenni, A. J., and Möhler, O.: Laboratory investigations of the impact of mineral dust aerosol on cold cloud formation, Atmos. Chem. Phys., 10, 11955-11968, doi:10.5194/acp10-11955-2010, 2010.

Lagriffoul, A., Boudenne, J. L., Absi, R., Ballet, J. J., Berjeaud, J. M., Chevalier, S., Creppy, E. E., Gilli, E., Gadonna, J. P., Gadonna-Widehem, P., Morris, C. E., and Zini, S.: Bacterialbased additives for the production of artificial snow: what are the risks to human health?, Sci. Total. Environ., 408, 1659-66, 2010. 
Langham, E. J. and Mason, B. J.: The Heterogeneous and Homogeneous Nucleation of Supercooled Water, P. Roy. Soc. A-Math. Phy., 247, 493-504, 1958.

LeGrand Jr., H. E. and Wiecek, C.: Inventory of significant natural areas in Wake County, North Carolina, North Carolina Natural Heritage Program, Division of Parks and Recreation, Dept. of Environment and Natural Resources, Raleigh, North Carolina, available at: http://cdm16062.contentdm.oclc.org/cdm/ref/ collection/p249901coll22/id/191094 (last access: 2 June 2014), 2003.

Levine, J.: Statistical explanation of spontaneous freezing of water droplets, National Advisory Committee for Aeronautics, Tech. Note 2234, 1950.

Maki, L. R., Galyan, E. L., Chang-Chien, M., and Caldwell, D. R.: Ice Nucleation Induced by Pseudomonas syringae, Appl. Microbiol., 28, 456-459, 1974.

Möhler, O., DeMott, P. J., Vali, G., and Levin, Z.: Microbiology and atmospheric processes: the role of biological particles in cloud physics, Biogeosciences, 4, 1059-1071, doi:10.5194/bg-4-10592007, 2007.

Möhler, O., Benz, S., Saathoff, H., Schnaiter, M., Wagner, R., Schneider, J., Walter, S., Ebert, V., and Wagner, S.: The effect of organic coating on the heterogeneous ice nucleation efficiency of mineral dust aerosols, Environ. Res. Lett., 3, 025007, doi:10.1088/1748-9326/3/2/025007, 2008.

Mossop, S. C.: Atmospheric ice nuclei, ZAMP-Z. Angew. Math. Phys., 14, 456-486, doi:10.1007/BF01601253, 1963.

Murray, B. J., O'Sullivan, D., Atkinson, J. D., and Webb, M. E.: Ice nucleation by particles immersed in supercooled cloud droplets, Chem. Soc. Rev., 41, 6519-54, doi:10.1039/c2cs35200a, 2012.

Noh, Y. M., Lee, H., Mueller, D., Lee, K., Shin, D., Shin, S., Choi, T. J., Choi, Y. J., and Kim, K. R.: Investigation of the diurnal pattern of the vertical distribution of pollen in the lower troposphere using LIDAR, Atmos. Chem. Phys., 13, 7619-7629, doi:10.5194/acp-13-7619-2013, 2013.

O'Sullivan, D., Murray, B. J., Malkin, T. L., Whale, T., Umo, N. S., Atkinson, J. D., Price, H. C., Baustian, K. J., Browse, J., and Webb, M. E.: Ice nucleation by soil dusts: relative importance of mineral dust and biogenic components, Atmos. Chem. Phys. Discuss., 13, 20275-20317, doi:10.5194/acpd-13-202752013, 2013.

Ogden, E. C. and Hayes, J. V.: Diurnal Patterns of Pollen Emission in Ambrosia, Phleum, Zea, and Ricinus, Am. J. Bot., 56, 16-21, doi:10.2307/2440389, 1969.

Pasanen, A., Pasanen, P., Jantunen, M. J., and Kalliokoski, P.: Significance of air humidity and air velocity for fungal spore release into the air, Atmos. Environ., 25A, 459-462, 1991.

Paul, P. A., El-Allaf, S. M., Lipps, P. E., and Madden, L. V: Rain Splash Dispersal of Gibberella zeae Within Wheat Canopies in Ohio, Phytopathology, 94, 1342-9, doi:10.1094/PHYTO.2004.94.12.1342, 2004.

Petters, M. D., Wex, H., Carrico, C. M., Hallbauer, E., Massling, A., McMeeking, G. R., Poulain, L., Wu, Z., Kreidenweis, S. M., and Stratmann, F.: Towards closing the gap between hygroscopic growth and activation for secondary organic aerosol - Part 2: Theoretical approaches, Atmos. Chem. Phys., 9, 3999-4009, doi:10.5194/acp-9-3999-2009, 2009.

Pöschl, U., Martin, S. T., Sinha, B., Chen, Q., Gunthe, S. S., Huffman, J. A., Borrmann, S., Farmer, D. K., Garland, R. M.,
Helas, G., Jimenez, J. L., King, S. M., Manzi, A., Mikhailov, E., Pauliquevis, T., Petters, M. D., Prenni, A. J., Roldin, P., Rose, D., Schneider, J., Su, H., Zorn, S. R., Artaxo, P., and Andreae, M. O.: Rainforest aerosols as biogenic nuclei of clouds and precipitation in the Amazon, Science, 329, 1513-1516, doi:10.1126/science.1191056, 2010.

Pratt, K. A., DeMott, P. J., French, J. R., Wang, Z., Westphal, D. L., Heymsfield, A. J., Twohy, C. H., Prenni, A. J., and Prather, K. A.: In situ detection of biological particles in cloud ice-crystals, Nat. Geosci., 2, 398-401, doi:10.1038/ngeo521, 2009.

Prenni, A. J., Petters, M. D., Kreidenweis, S. M., Heald, C. L., Martin, S. T., Artaxo, P., Garland, R. M., Wollny, A. G., and Pöschl, U.: Relative roles of biogenic emissions and Saharan dust as ice nuclei in the Amazon basin, Nat. Geosci., 2, 402-405, 2009.

Prenni, A. J., Tobo, Y., Garcia, E., DeMott, P. J., Huffman, J. A., McCluskey, C. S., Kreidenweis, S. M., Prenni, J. E., Pöhlker, C., and Pöschl, U.: The impact of rain on ice nuclei populations at a forested site in Colorado, Geophys. Res. Lett., 40, 227-231, doi:10.1029/2012GL053953, 2013.

Pruppacher, H. R. and Klett, J. D.: Microphysics of Clouds and Precipitation, 2nd Edn., edited by: Rosen, R. D., Kluwer Academic Publishers, Dordrecht, the Netherlands, 1997.

Pummer, B. G., Bauer, H., Bernardi, J., Bleicher, S., and Grothe, H.: Suspendable macromolecules are responsible for ice nucleation activity of birch and conifer pollen, Atmos. Chem. Phys. 12, 2541-2550, doi:10.5194/acp-12-2541-2012, 2012.

Richard, C., Martin, J., and Pouleur, S.: Ice nucleation activity identified in some phytopathogenic Fusarium species, Phytoprotection, 77, 83-92, doi:10.7202/706104ar, 1996.

Riediker, M., Koller, T., and Monn, C.: Differences in size selective aerosol sampling for pollen allergen detection using highvolume cascade impactors, Clin. Exp. Allergy, 30, 867-873, doi:10.1046/j.1365-2222.2000.00792.x, 2000.

Roberts, P. and Hallett, J.: A laboratory study of the ice nucleating properties of some mineral particulates, Q. J. Roy. Meteor. Soc., 94, 25-34, doi:10.1002/qj.4970, 1968.

Schnell, R. C. and Vali, G.: Biogenic Ice Nuclei: Part I. Terrestrial and Marine Sources, J. Atmos. Sci., 33, 1554-1564, doi:10.1175/1520-0469(1976)033<1554: $\mathrm{BINPIT>2.0.CO;2,}$ 1976.

Sear, R. P.: Generalisation of Levine's prediction for the distribution of freezing temperatures of droplets: a general singular model for ice nucleation, Atmos. Chem. Phys., 13, 7215-7223, doi:10.5194/acp-13-7215-2013, 2013.

Shaw, R. A., Durant, A. J., and Mi, Y.: Heterogeneous surface crystallization observed in undercooled water, J. Phys. Chem. B, 109, 9865-9868, doi:10.1021/jp0506336, 2005.

Sullivan, R. C., Miñambres, L., DeMott, P. J., Prenni, A. J., Carrico, C. M., Levin, E. J. T., and Kreidenweis, S. M.: Chemical processing does not always impair heterogeneous ice nucleation of mineral dust particles, Geophys. Res. Lett., 37, 1-5, 2010a.

Sullivan, R. C., Petters, M. D., DeMott, P. J., Kreidenweis, S. M., Wex, H., Niedermeier, D., Hartmann, S., Clauss, T., Stratmann, F., Reitz, P., Schneider, J., and Sierau, B.: Irreversible loss of ice nucleation active sites in mineral dust particles caused by sulphuric acid condensation, Atmos. Chem. Phys., 10, 1147111487, doi:10.5194/acp-10-11471-2010, 2010 b.

Suphioglu, C., Singh, M. B., Taylor, P., Knox, R. B., Bellomo, R., Holmes, P., and Puy, R.: Mechanism of grass-pollen- 
induced asthma, The Lancet, 339, 569-572, doi:10.1016/01406736(92)90864-Y, 1992.

Taylor, P. E., Flagan, R. C., Valenta, R., and Glovsky, M. M.: Release of allergens as respirable aerosols: A link between grass pollen and asthma, J. Allergy Clin. Immun., 109, 51-56, doi:10.1067/mai.2002.120759, 2002.

Vali, G.: Quantitative Evaluation of Experimental Results on the Heterogeneous Freezing Nucleation of Supercooled Liquids, J. Atmos. Sci., 28, 402-409, doi:10.1175/15200469(1971)028<0402:QEOERA>2.0.CO;2, 1971.

Vali, G.: Freezing rate due to heterogeneous nucleation, J. Atmos. Sci., 51, 1843-1856, 1994.

von Blohn, N., Mitra, S. K., Diehl, K., and Borrmann, S.: The ice nucleating ability of pollen, Atmos. Res., 78, 182-189, doi:10.1016/j.atmosres.2005.03.008, 2005

von der Weiden, S.-L., Drewnick, F., and Borrmann, S.: Particle Loss Calculator - a new software tool for the assessment of the performance of aerosol inlet systems, Atmos. Meas. Tech., 2, 479-494, doi:10.5194/amt-2-479-2009, 2009.
Webster, J., Davey, R., and Ingold, C. T.: Origin of the liquid in Buller's drop, Trans. Br. Mycol. Soc., 83, 524-527, doi:10.1016/S0007-1536(84)80055-8, 1984.

Willeke, K., Lin, X., and Grinshpun, S. A.: Improved Aerosol Collection by Combined Impaction and Centrifugal Motion, Aerosol Sci. Technol., 28, 439-456, 1998.

Williams, C. G.: Long-distance pine pollen still germinates after meso-scale dispersal, Am. J. Bot., 97, 846-55, doi:10.3732/ajb.0900255, 2010

Williams, C. G.: Forest tree pollen dispersal via the water cycle, Am. J. Bot., 100, 1184-90, doi:10.3732/ajb.1300085, 2013.

Wright, T. P. and Petters, M. D.: The role of time in heterogeneous freezing nucleation, J. Geophys. Res.-Atmos., 118, 3731-3743, doi:10.1002/jgrd.50365, 2013.

Wright, T. P., Petters, M. D., Hader, J. D., Morton, T., and Holder, A. L.: Minimal cooling rate dependence of ice nuclei activity in the immersion mode, J. Geophys. Res.-Atmos., 118, 1-9, doi:10.1002/jgrd.50810, 2013. 